\title{
The Antibiotic Relationships of Some Free-living Bacteria
}

\author{
By J. D. STOUT \\ Soil Bureau Experimental Station, Eastern Hutt Road, Lower Hutt, New Zealand
}

(Received 15 May 1961)

SUMMARY

The sensitivity to antibiotics and the reactions to antibiotic-producing bacteria, streptomyces and fungi of a range of bacteria isolated from soil, leaves and forest litter showed broad differences between the Gram-positive and Gram-negative organisms, the fermentative and non-fermentative ones, and, to a lesser extent, between those of leaf origin and those of soil origin. These differences are not alone sufficient to explain the differences between the leaf flora and the soil flora. Other factors, including the capacity to produce antibiotics, are also important.

\section{INTRODUCTION}

The most distinct boundary separating natural populations of bacteria is that which divides the flora of the growing leaf (epiphytic flora) from the soil flora. Despite the very large populations which may obtain on leaves, such as those of pasture plants, in close proximity to the soil surface there is a rapid depletion of the epiphytic bacteria eluted into the soil so that few survive within the profile (Stout, 1960 $b$ ). The biochemical and other physiological properties of the epiphytic bacteria do not appear to be very different from those of the common soil bacteria and it is difficult to attribute the failure of the epiphytic flora to colonize soil to their nutritional or other physiological shortcomings. One feature of the epiphytic flora, however, is the absence or virtual absence of streptomyces and the comparatively small numbers of fungi and spore-forming bacteria. These organisms are common in soil and are the most notable sources of antibiotic substances (Spector, 1957). It has therefore been thought possible that the extinction of the epiphytic flora in soil is due to microbial antagonisms and, in particular, to the effects of antibiotic substances. To test this hypothesis a range of bacterial isolates from various habitats (leaf, forest litter, soil) were tested against a selection of antibiotic substances produced by fungi, streptomyces and bacteria and against living fungi, yeasts, streptomyces and bacteria.

\section{MATERIALS AND METHODS}

The bacteria tested were isolated during recent years in the course of a survey of the grasslands, peats and forests of New Zealand. They have been classified as far as possible according to Bergey's Manual (1957). Further taxonomic and ecological details are given elsewhere (Stout, 1958, 1960a,b). Altogether 93 strains were used.

The antibiotic substances used are listed in Table 1 which also gives the source, the preparation, the diluent, and the concentrations tested. The bacterial and streptomycete antibiotics were generally readily soluble but some of the fungal antibiotics 


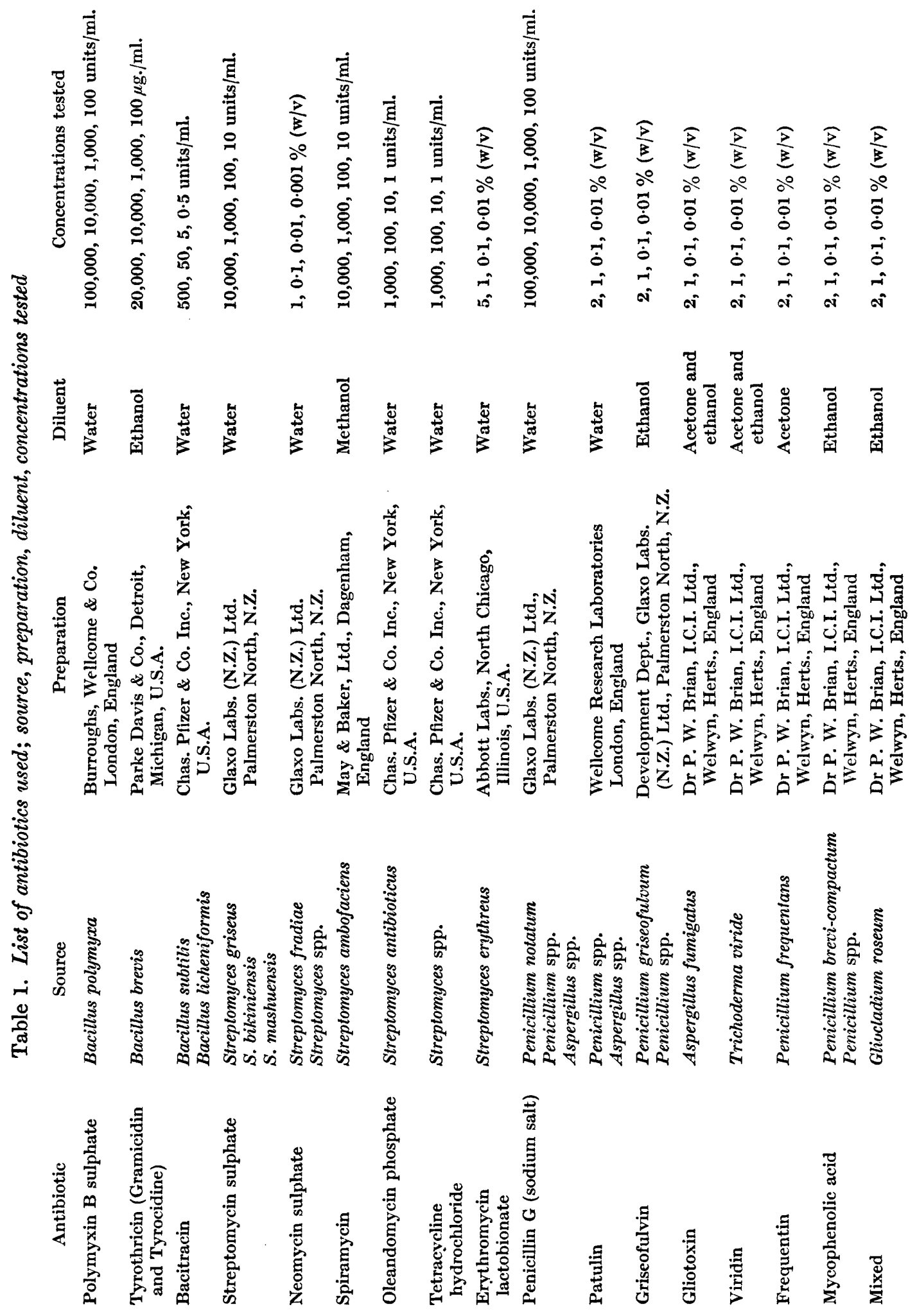


were difficult to dissolve. Tests with acetone and ethanol showed that these solvents did not themselves inhibit growth in the concentrations used.

Broth cultures of the bacteria were prepared and used to inoculate agar plates which for most of the experiments consisted of tryptone $(0 \cdot 1 \%)$, Difco yeast extract $(0.1 \%)$, agar $(1.5 \%)$, made up in distilled water. Potato carrot agar was used in experiments with the streptomycete plugs. This medium consisted of diced potatoes $(20 \mathrm{~g}$.$) and carrots (20 \mathrm{~g}$.), steamed in $1 \mathrm{l}$. distilled water for $20 \mathrm{~min}$.; this was then filtered, made up to 11 ., agar added to $1.5 \%(\mathrm{w} / \mathrm{v})$ and autoclaved. Four filter paper disks $(1 \mathrm{~cm}$.) impregnated with the appropriate dilutions of the selected antibiotic were used for each plate. The total diameter of the zone of inhibition was measured after incubation for $24 \mathrm{hr}$. at $25^{\circ}$ and summed for each plate.

The reproducibility of the technique was tested on several occasions with reasonably satisfactory results (Table 2 ). Consequently only a single plate was poured for each isolate tested. Strain variation (Table 3) did not appear to be important with

\section{Table 2. Results of duplicate plating}

Sum of the diameters of the four zones of inhibition for each plate in $\mathrm{mm}$.

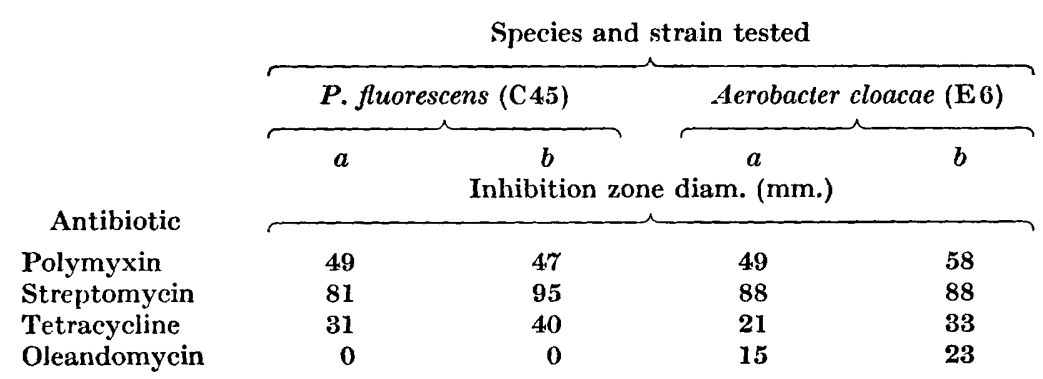

Table 3. Strain variation

Sum of the diameters of the four zones of inhibition for each plate in mm. n.d. = not done.

\begin{tabular}{|c|c|c|c|c|c|}
\hline \multirow[b]{3}{*}{ Antibiotic } & \multicolumn{5}{|c|}{ Species and strain tested } \\
\hline & \multicolumn{2}{|c|}{ Chromobacterium lividum } & \multicolumn{3}{|c|}{ Bacillus cereus } \\
\hline & $45 / 1 / 3$ & $45 / 1 / 25$ & $60 / 2 / 79$ & $60 / 2 / 121$ & $60 / 21 / 2$ \\
\hline Polymyxin & 35 & 29 & 61 & n.d. & 63 \\
\hline Tyrothricin & 0 & 0 & $\mathbf{0}$ & n.d. & $\mathbf{3 0}$ \\
\hline Bacitracin & o & $\mathbf{0}$ & $\mathbf{0}$ & n.d. & 20 \\
\hline Streptomycin & 72 & 45 & 102 & n.d. & 102 \\
\hline Neomycin & 81 & 25 & 47 & 45 & 52 \\
\hline Spiramycin & 0 & 0 & 25 & 40 & 26 \\
\hline Oleandomycin & $\mathbf{3 0}$ & 37 & $7 \%$ & n.d. & 65 \\
\hline Tetracycline & 45 & 16 & 58 & n.d. & 51 \\
\hline Erythromycin & 85 & 61 & 0 & 109 & 111 \\
\hline Penicillin & 88 & 0 & 0 & 40 & 70 \\
\hline Patulin & 65 & 50 & 10 & $\mathbf{5 8}$ & 70 \\
\hline Grise ofulvin & 0 & 0 & $\mathbf{0}$ & $\mathbf{0}$ & 10 \\
\hline Gliotoxin & $\mathbf{0}$ & 0 & 87 & 142 & 111 \\
\hline Viridin & 20 & $\mathbf{2 3}$ & 108 & 142 & 130 \\
\hline Frequentin & $\mathbf{0}$ & 10 & 0 & 37 & 23 \\
\hline Mycophenolic acid & $\mathbf{0}$ & 0 & 10 & 10 & 10 \\
\hline Mixed (Gliocladium) & 25 & 25 & 46 & $\mathbf{5 3}$ & 30 \\
\hline
\end{tabular}


the Gram-negative bacteria, e.g. Chromobacterium, but was more significant with the bacilli, particularly Bacillus cereus. The strains of $\boldsymbol{B}$. cereus used were, however, as diverse as possible, one having been isolated as a smooth mucoid form, another as a pigmented form, and a third the more typical rough cream form.

For testing the inhibition of bacterial growth by other organisms two techniques were used, the plug method and the streak method. In the plug method the test organisms (fungi, yeasts, streptomyces) were grown on the soya bean agar plates (Smith, Gordon \& Clark, 1952) for 14 days. Plugs of agar (0.6 mm. diameter) were then cut and placed on the bacterial plates (four to a plate) and the zone of inhibition measured in the same way as with the antibiotic disks. In the streak method soya bean agar plates were streaked with the test organisms (bacteria, yeasts) in four parallel lines and the plates incubated for 7 days. Loops of broth cultures of the different bacteria were then streaked between these initial inocula and the degree of growth arbitrarily assessed. Four degrees were recognized: no growth, slight growth, moderate growth, and good growth, which were scored, respectively, 0, 1, 2, 3. Neither of these techniques was wholly satisfactory, the plug method being superior to the streak method. The latter was used, however, principally for the bacteria for which the plug method was clearly unsuitable because of their rapid and spreading growth on the tryptone yeast-extract agar. In the event, both methods provided a better index of antibiotic-producing organisms rather than of antibioticsensitive organisms. This was particularly so with the streak method, for it was observed with the control plates that certain of the bacterial strains tested grew very poorly on the soya bean agar plates while others grew very well.

\section{RESULTS}

Inhibition of bacterial growth by antibiotic substances

Comparison of the efficacy of the different antibiotic substances is qualified by their differences in purity, solubility, and the concentrations tested. Of the seventeen antibiotics tested only griseofulvin proved virtually ineffective. The results are given in Table 4. These show:

(a) The Gram-positive bacteria (Micrococcus, Sarcina, Bacillus, Nocardia) were more sensitive than the Gram-negative bacteria (Pseudomonas, Xanthomonas, Aeromonas, Flavobacterium, Achromobacterium, Chromobacterium, Aerobacter, Escherichia and Serratia).

(b) The aerogenic fermenters (Aeromonas, Flavobacterium sp. Type IV, Serratia, Escherichia and Bacillus polymyxa) tended to be relatively insensitive, but Escherichia coli appeared to be more sensitive than the other Gram-negative aerogenic fermenters.

(c) The Gram-negative bacteria of leaf origin (Xanthomonas, Flavobacterium) were generally more sensitive than those commonly found in soil (Pseudomonas) but the dominant leaf taxon Flavobacterium Type I was no more sensitive than the pseudomonads or the aerogenic fermenters.

\section{Inhibition of bacterial growth by streptomycete and fungal plugs}

The pattern of bacterial sensitivity to these inhibitory moulds and streptomyces was similar to that of the antibiotics. Of the Gram-negative bacteria, only the flavobacteria showed inhibition, the pseudomonads and aerogenic fermenters were 


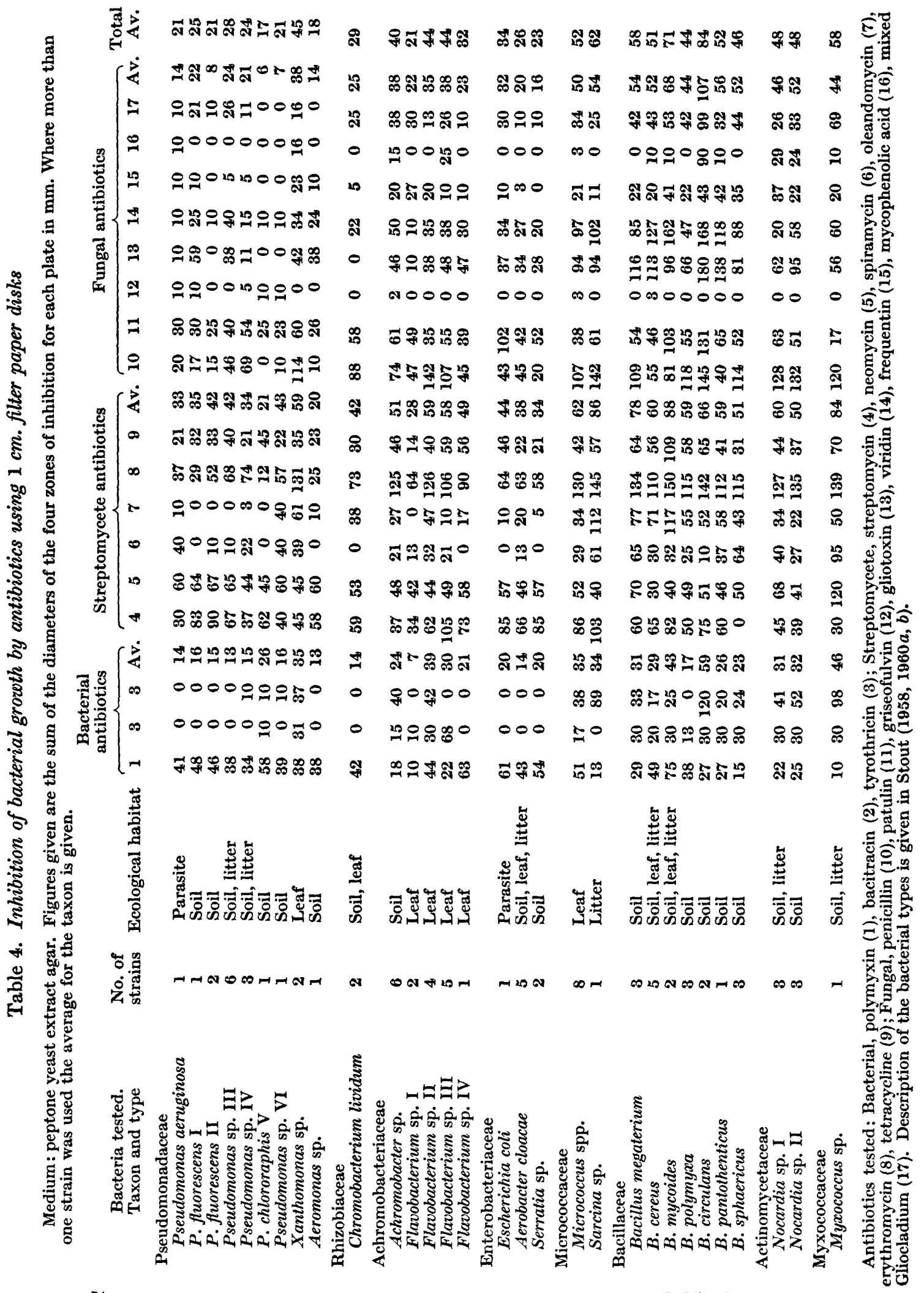


insensitive. Inhibition occurred most commonly with the Gram-positive bacteria although one strain of Micrococcus proved insensitive to the streptomycete plugs, and a strain of Sarcina and the majority of the Bacillus species were unaffected by the moulds. The results are given in Tables 5 and 6. Most of the streptomyces tested showed inhibitory activity against some bacterial strains although the two strains of Streptomyces hygroscopicus (Table 5, nos. 4 and 5) were appreciably more effective than the others. The pattern of bacterial sensitivity resembled that shown by the streptomycete antibiotics.

Table 5. Inhibition of bacterial growth in potato carrot agar by 8 streptomycete plugs grown on soya bean agar

All the Pseudomonodaceae (nine strains), Rhizobiaceae (one strain) and Enterobacteriaceae (four strains) tested showed no inhibition. Figures given are the sum of the diameters of the four zones of inbibition for each plate in $\mathrm{mm}$. Where more than one strain was used the average for the taxon is given.

Bacteria tested. Taxa

Streptomycete plugs used

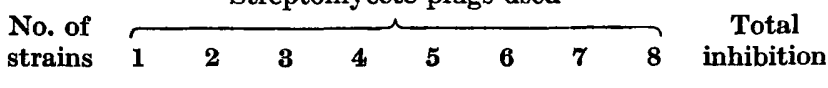

Achromobacteriaceae

Flavobacterium sp. I

Flavobacterium sp. II

Flavobacterium sp. III

Flavobacterium sp. IV

Flavobacterium sp.

Flavobacterium sp.

Flavobacterium sp.

Flavobacterium sp.

Micrococcaceae

Micrococcus sp.

Micrococcus sp.

Bacillaceae

Bacillus cereus

B. mycoides

Actinomycetaceae

Nocardia sp.

Nocardia sp.

Total inhibition

No. taxa inhibited

$\begin{array}{rrrrrrrrrr}\mathbf{3} & \mathbf{0} & \mathbf{0} & \mathbf{0} & \mathbf{0} & \mathbf{0} & \mathbf{0} & \mathbf{0} & \mathbf{0} & \mathbf{0} \\ \mathbf{1} & \mathbf{9} & \mathbf{9} & \mathbf{8} & \mathbf{1 8} & \mathbf{1 3} & \mathbf{8} & \mathbf{9} & \mathbf{0} & \mathbf{7 4} \\ \mathbf{1} & \mathbf{8} & \mathbf{9} & \mathbf{8} & \mathbf{2 0} & \mathbf{2 6} & \mathbf{0} & \mathbf{8} & \mathbf{0} & \mathbf{7 9} \\ \mathbf{1} & \mathbf{0} & \mathbf{0} & \mathbf{0} & \mathbf{0} & \mathbf{0} & \mathbf{0} & \mathbf{0} & \mathbf{0} & \mathbf{0} \\ \mathbf{3} & \mathbf{7} & \mathbf{3} & \mathbf{2} & \mathbf{1 5} & \mathbf{1 5} & \mathbf{0} & \mathbf{2} & \mathbf{0} & \mathbf{4 4} \\ \mathbf{1} & \mathbf{0} & \mathbf{0} & \mathbf{0} & \mathbf{0} & \mathbf{0} & \mathbf{0} & \mathbf{0} & \mathbf{0} & \mathbf{0} \\ \mathbf{2} & \mathbf{0} & \mathbf{0} & \mathbf{0} & \mathbf{0} & \mathbf{0} & \mathbf{6} & \mathbf{0} & \mathbf{0} & \mathbf{6} \\ \mathbf{1} & \mathbf{1 0} & \mathbf{1 1} & \mathbf{0} & \mathbf{0} & \mathbf{2 6} & \mathbf{8} & \mathbf{1 0} & \mathbf{6} & \mathbf{7 1} \\ & & & & & & & & & \\ \mathbf{1} & \mathbf{1 7} & \mathbf{8} & \mathbf{9} & \mathbf{2 2} & \mathbf{1 9} & \mathbf{0} & \mathbf{6} & \mathbf{6} & \mathbf{8 7} \\ \mathbf{1} & \mathbf{0} & \mathbf{0} & \mathbf{0} & \mathbf{0} & \mathbf{0} & \mathbf{0} & \mathbf{0} & \mathbf{0} & \mathbf{0} \\ & & & & & & & & & \\ \mathbf{2} & \mathbf{0} & \mathbf{3} & \mathbf{0} & \mathbf{1 4} & \mathbf{1 8} & \mathbf{0} & \mathbf{0} & \mathbf{3} & \mathbf{3 3} \\ \mathbf{1} & \mathbf{0} & \mathbf{0} & \mathbf{0} & \mathbf{1 8} & \mathbf{1 8} & \mathbf{0} & \mathbf{0} & \mathbf{0} & \mathbf{3 6} \\ & & & & & & & & & \\ \mathbf{1} & \mathbf{1 2} & \mathbf{0} & \mathbf{0} & \mathbf{1 8} & \mathbf{2 2} & \mathbf{0} & \mathbf{0} & \mathbf{0} & \mathbf{5 2} \\ \mathbf{1} & \mathbf{0} & \mathbf{0} & \mathbf{0} & \mathbf{2 6} & \mathbf{1 6} & \mathbf{0} & \mathbf{8} & \mathbf{0} & \mathbf{5 0} \\ & \mathbf{6 3} & \mathbf{4 3} & \mathbf{2 7} & \mathbf{1 5 1} & \mathbf{1 6 8} & \mathbf{2 2} & \mathbf{4 8} & \mathbf{1 5} & \mathbf{5 3 2} \\ & \mathbf{6} & \mathbf{6} & \mathbf{4} & \mathbf{8} & \mathbf{9} & \mathbf{3} & \mathbf{6} & \mathbf{3} & \mathbf{1 0}\end{array}$

The few fungi which showed inhibitory activity included the most commonly recorded antibiotic-producing genera, namely Aspergillus, Penicillium, Gliocladium, Fusarium and particularly Trichoderma (see Spector, 1957). Trichoderma viride was easily the most effective. Aspergillus fumigatus, Gliocladium roseum, Penicillium frequentans, Fusarium culmorum and Cylindrocarpon radicicola were effective against one or two bacterial strains. The dominant soil fungi, such as Rhizoctonia (Thornton, 1958), and the fungi found on leaves (Pithomyces chartarum syn. Sporidesmium bakeri and Stemphylium) were ineffective.

Inhibition by Trichoderma viride generally resembled the pattern of sensitivity to viridin but was not absolutely identical. Thus Bacillus mycoides and $\boldsymbol{B}$. circulans, the two organisms most sensitive to viridin, were also sensitive to $T$. viride, but other viridin-sensitive bacilli, such as $B$. cereus and $\boldsymbol{B}$. megaterium, were not. 


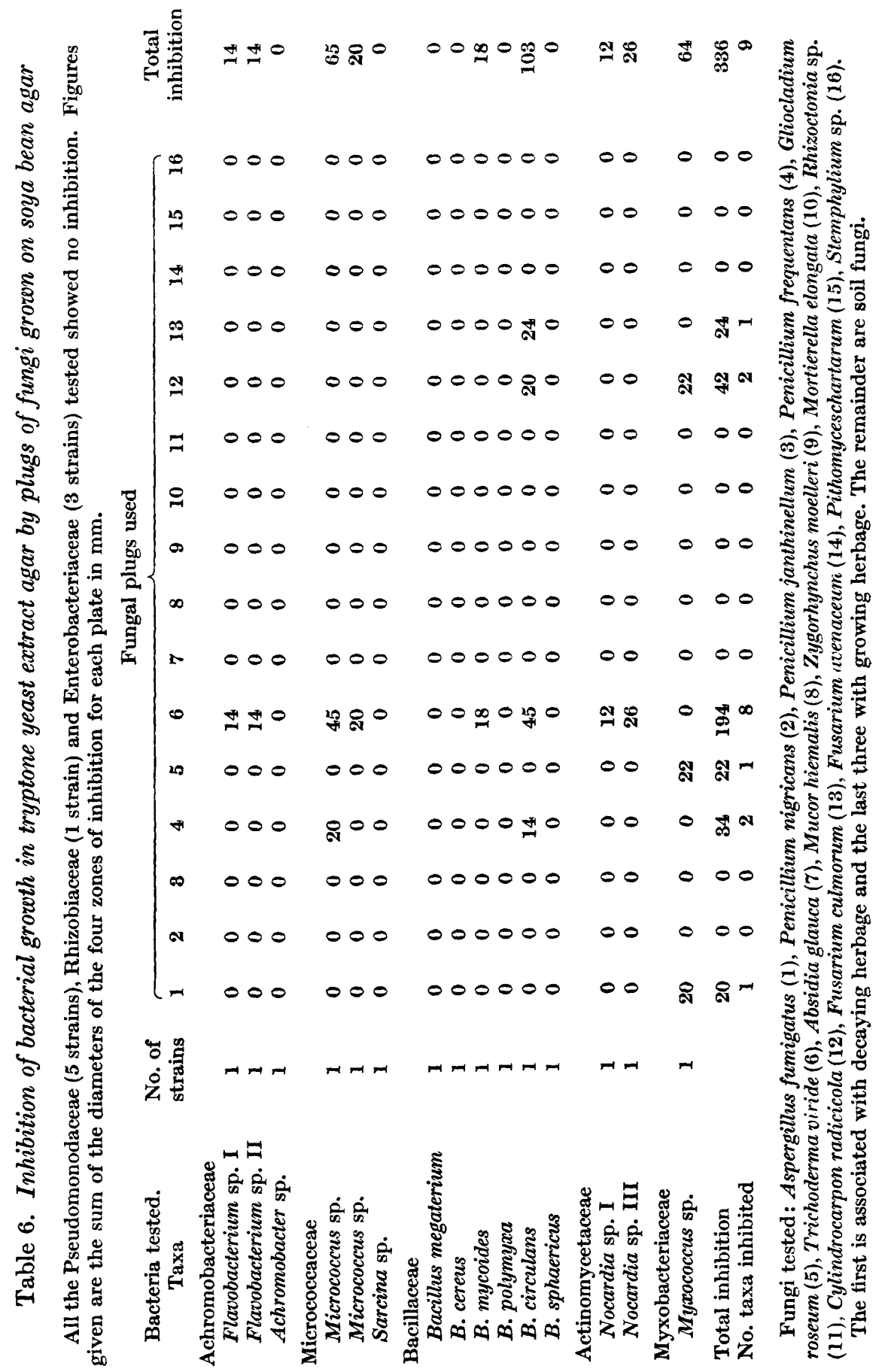




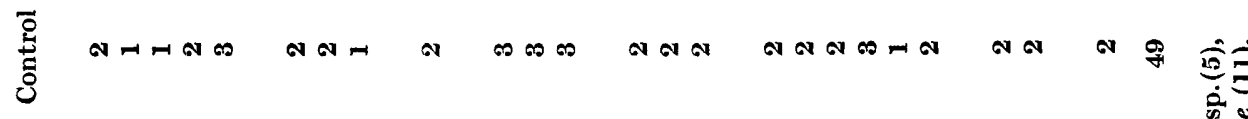

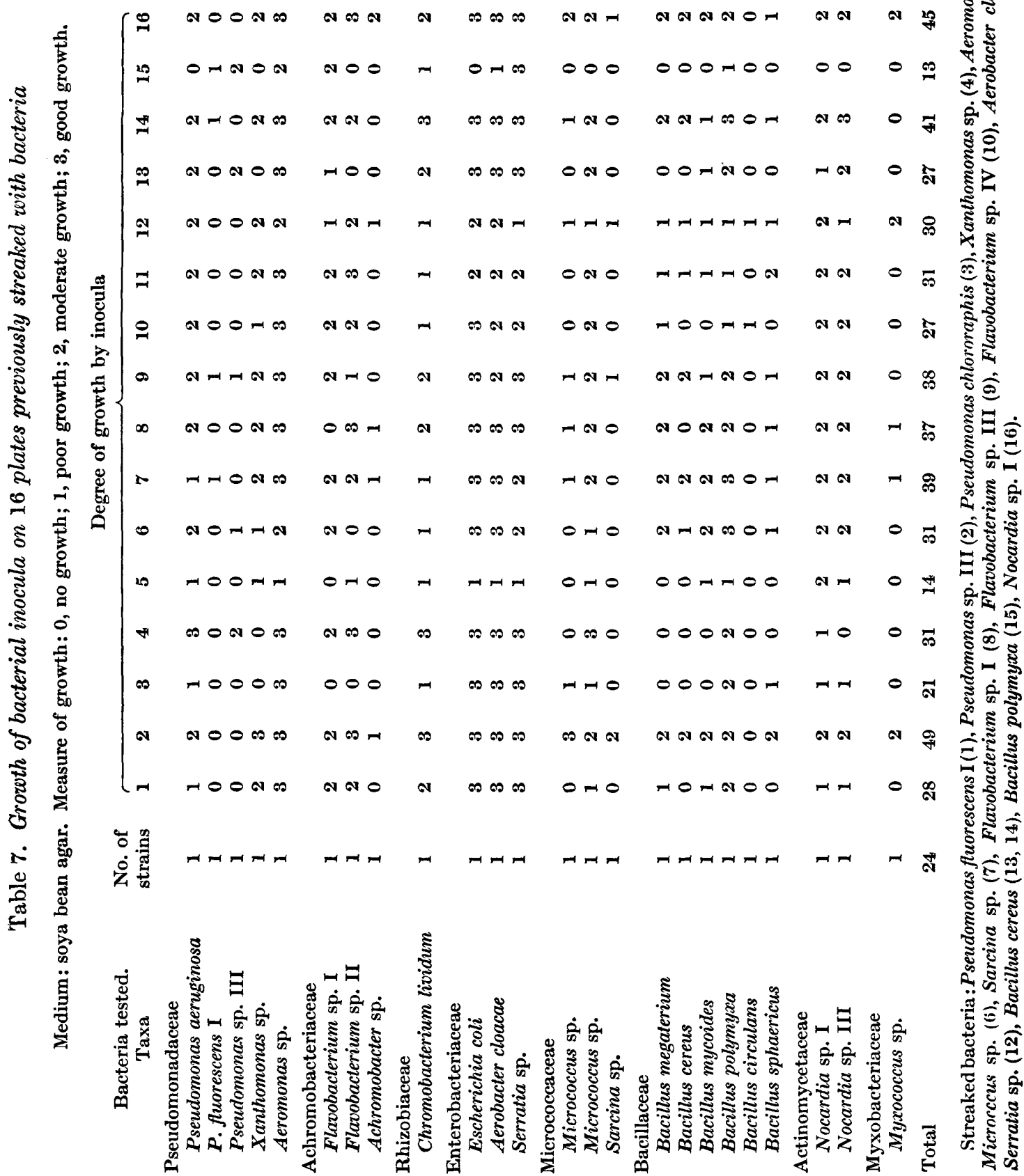




\section{Antibiotic relationships of bacteria}

Similarly, Micrococcus but not Sarcina was inhibited by the fungus though both were sensitive to viridin; and the flavobacteria and nocardias were inhibited by the fungus though they were not particularly sensitive to viridin.

The same bacterial strains used in the fungi tests were also tested against eight yeasts (Cryptococcus laurentii, C. albidus, Rhodotorula marina, Candida curvata, C. humicola, Hansenula saturnis, Trichosporon cutaneum, Sporobolomyces roseus). The results were inconclusive. There was no evidence of inhibition on the streak plates but on the plug plates some bacteria (Xanthomonas, Aeromonas, Flavobacterium) showed a very slight zone of inhibition round the plug. Since the yeasts grew on the sides of the plug and on to the surface of the plate after inoculation the significance of this very limited inhibition is not clear. It may have been due to competition for nutrients, but since Aeromonas, a facultative anaerobe, was affected it could not have been due in this case at least to induced anaerobiosis under the plug.

\section{Inhibitory effect of bacterial streak plates}

The results are shown in Table 7. Some bacteria (e.g. the aerogenic fermenters) grew well while others (e.g. some pseudomonads and bacilli) grew very poorly on the soya bean agar pre-streaked with bacteria. This was due partly to the limited nutrient status of the agar and partly to its desiccation during the period of incubation when the bacterial streaks were growing. Consequently, these plates did not give a clear picture of the relative sensitivity of the different taxa tested. However, the results did indicate that certain of the streaked bacteria, namely Bacillus polymyxa, Aeromonas, and Pseudomonas chlororaphis, did possess appreciably greater inhibitory powers than the other strains. Aeromonas and $\boldsymbol{P}$. chlororaphis also proved to be two of the most effective bacteria in inhibiting the growth of yeasts (di Menna, 1961).

\section{DISCUSSION}

The present evidence does not support the thesis that sensitivity to antibiotics is a major factor in the discontinuous distribution of free-living bacteria. The principal taxon found on pasture leaves, often in enormous numbers and commonly absent from soil, namely Flavobacterium Type I (see Stout, $1960 b$ ), is no more sensitive to these antibiotics than the common soil pseudomonads. Other minor leaf taxa, however, are more sensitive and consequently may be excluded from the soil by this factor. The most sensitive group are the aerobic spore-forming bacilli which are amongst the most widespread and numerous of soil organisms. Clearly other attributes are more important in determining the ecology of these bacteria. One such attribute may be the capacity to produce antibiotics (see Brian, 1957). In this respect the bacilli and nocardias, typical soil bacteria, are the most commonly recorded bacterial sources of antibiotics (Spector, 1957). In the present experiments both Bacillus polymyxa and Pseudomonas chlororaphis appeared to have some inhibitory effect on bacterial growth. This conforms to their known production of polymyxin and chlororaphin, respectively (Florey et al. 1949). It is interesting to note that polymyxin also inhibited the growth of $\boldsymbol{B}$. polymyxa. A similar situation obtains with megacin and $B$. megaterium (Ivánovics \& Nagy, 1958). A possible explanation of this curious anomaly, at variance with the fungal evidence (Brian, 
1957), is that the antibiotic is produced during spore formation (Bernlohr \& Novelli, 1959) and the spores, as distinct from the vegetative cells, may be unaffected.

Although Pseudomonas fuorescens is often dominant in the indigenous grassland soils of New Zealand (Stout, 1958) and in the exotic pastures developed from them (Stout, $1960 a$ ), $P$. aeruginosa has not been isolated from these soils. There does not appear to be any distinction in their sensitivity to antibiotics to account for this difference in distribution between the saprophyte and the parasite. Similarly, although Escherichia coli may be recovered from herbage and from soil in a grazed pasture it does not appear to persist in either habitat, despite its relative tolerance of antibiotics.

The suggestion that sensitivity to antibiotics may afford a useful taxonomic criterion (Shewan, Hodgkiss \& Linton, 1954) receives some support from this study, though a wider range of strains of the individual taxa would need to be tested before it could be applied with confidence. Amongst suggestive results the complete insensitivity of both strains of Bacillus sphaericus tested to streptomycin at the concentrations used, was noteworthy, while some of the sharpest contrasts between different taxa were obtained with bacitracin and tyrothricin.

The strains of streptomyces used were kindly supplied by Dr T. R. Vernon (Plant Diseases Division, D.S.I.R., Mt. Albert, Auckland); the yeasts by my colleague Dr Margaret di Menna; and the fungi by Dr R. H. Thornton, formerly of this laboratory. I am indebted to Dr P. W. Brian, F.R.S. (I.C.I. Ltd., Welwyn, Herts., England), and to Glaxo Laboratories (N.Z.) for providing a number of the fungal antibiotics, and to Dr J. O. Mercer (Wellington Public Hospital, New Zealand) for supplying two of the bacterial antibiotics. I am also indebted to Miss M. K. Bennett for technical assistance.

This is Soil Bureau publication no. 252.

\section{REFERENCES}

Bergey's Manual of Determinative Bacteriology (1957). 7th ed. Ed. by R. S. Breed, E. G. D. Murray \& N. R. Smith. London: Baillière, Tindall \& Cox, Ltd.

Bernlohr, R. W. \& Noveldi, G. D. (1959). Antibiotic production as a function of spore formation in Bacillus licheniformis. Nature, Lond. 184, 1256.

Brian, P. W. (1957). The ecological significance of antibiotic production. In Microbial Ecology. Symp. Soc. gen. Microbiol. 7, 168.

Florey, H. W., Chain, E., Heatley, N. G., Jennings, M. A., Sanders, A. G., Abraham, E. P. \& Florey, M. E. (1949). Antibiotics. A survey of penicillin, streptomycin, and other antimicrobial substances from fungi, actinomycetes, bacteria, and plants. Vol. I. Oxford: University Press, Oxford Medical Publications.

IváNovics, G. \& NAGY, E. (1958). Hereditary aberrancy in growth of some Bacillus megaterium strains. J. gen. Microbiol. 19, 407.

di Menna, M. E. (1961). The antibiotic relationships of some yeasts from soil and leaves. J. gen. Microbiol. 27, 249.

Shewan, J. M., Hodgriss, W. \& Liston, J. (1954). A method for the rapid differentiation of certain non-pathogenic, asporogenous bacilli. Nature, Lond. 173, 208.

Smith, N. R., Gordon, R. E. \& Clark, F. E. (1952). Aerobic Sporeforming Bacteria. Monogr. U.S. Dep. Agric., no. 16.

Spector, W. S., ed. (1957). Handbook of Toxicology, vol. 2. Antibiotics. Philadelphia \& London: W. B. Saunders \& Co. 
STout, J. D. (1958). Biological studies of some tussock grassland soils. IV. Bacteria. N.Z. J. agric. Res. 1, 943.

StouT, J. D. $(1960 a)$. Biological studies of some tussock grassland soils. XV. Bacteria of two cultivated soils. N.Z. J. agric. Res. 3, 214.

Stout, J. D. (1960b). Bacteria of soil and pasture leaves at Claudelands showgrounds. N.Z. J. agric. Res. 3, 413.

Thornton, R. H. (1958). Biological studies of some tussock grassland soils. II. Fungi. N.Z. J. agric. Res. 1, 922. 